
\title{
25 Research Soure \\ Identifying the domains and factors influencing perceived Quality of Life (QoL) of Indian elderly in the context of their neighbourhoods: a case study of Kolkata, India
}

\section{Suparna Saha ( $\nabla$ ar.suparna.saha@gmail.com )}

National Institute of Technology, Rourkela, India; Indian Institute of Technology, Kharagpur, India

Sanghamitra Basu

Indian Institute of Technology, Kharagpur, India

Debapratim Pandit

Indian Institute of Technology, Kharagpur, India

\section{Research Article}

Keywords: Indian elderly, QoL factors and domains, Perceived QoL

Posted Date: April 19th, 2021

DOl: https://doi.org/10.21203/rs.3.rs-432566/v1

License: (c) (i) This work is licensed under a Creative Commons Attribution 4.0 International License.

Read Full License

Version of Record: A version of this preprint was published at Quality \&amp; Quantity on July 25th, 2022. See the published version at https://doi.org/10.1007/s11135-022-01419-4. 


\section{Abstract}

The concept of Quality of Life (QoL) is multi-dimensional and has been explored from varied perspectives. Though QoL is a multi-dimensional concept, research on QoL has been mostly explored from a limited set of aspects. The assessment of QoL of elderly have been so far mostly based on measurement models derived from the perspective of American or European elderly. The subjectivity of the concept of QoL and the distinct dissimilarities in the perspectives of the elderly living in South Asian countries seeks for the development of QoL models from their perspective. Besides, since a significant number of the elderly in South Asian countries prefer to age-in-place, the need to identify parameters to improve their QoL in their neighbourhood context also becomes important. This paper, explores the perspectives of a group of Indian elderly, and identifies a broad set of domains and their respective set of factors, influencing perceived QoL of Indian elderly, which can be supported through the residential environment. The factors have been identified through literature review, followed by qualitative analysis of focus group discussions and quantitative analysis of close-ended interviews with Indian elderly across varied socio-demographic backgrounds. The present study, identifies seven broad domains and $37 \mathrm{QoL}$ factors influencing perceived QoL of Indian elderly.

\section{Introduction}

The gradual depletion of the traditional multi-generational family systems, which have been providing home-based care for the elderly in South Asian countries, including India, (Ugargol, Hutter, James, \& Bailey, 2016) along with rise in the population of the Indian elderly (Kalavar \& Jamuna, 2008) are thrusting the responsibility of care-giving for the elderly on the government, consequently leading to a growing need to develop policies and programmes for the welfare and well-being of the aged in the country. Deteriorating health conditions, loss in level of independence, and decrease in social support due to the death and illness of family members and friends leads to a decline in the QoL of elderly (Bowling 2011), The physical limitations resulting from age related limitations and disorders, in many cases, restrict the daily activities and interactions of the elderly to the their residential areas. Besides, in India the costs involved in institutional care and the social taboo associated with the institution of old age homes (Brijnath, 2012), increases the preference of the elderly to age-in-place. Aging-in-place also helps the elderly to continue living in their familiarized lifestyle (Jayantha, Qian, \& Yi, 2018; Kendig, Gong, Cannon, \& Browning, 2017; Tang \& Pickard, 2008). The present study, identifies the factors of QoL which can be catered to by the neighborhood environment.

The concept of QoL has been explored from two perspectives: subjective and objective. Subjective QoL deals with an individual's perceptions of various aspects of life based on his/ her background, perceptions, emotional and physical status. The subjective approach to defining QoL was also recommended by World Health Organisation (WHOQOLGroup, 1995). The subjective approach suggests that the perception of QoL and the factors that people associate with it are influenced by their social and cultural settings (Halvorsrud \& Kalfoss, 2007; Nilsson, Grafström, Zaman, \& Kabir, 2005). Effective 
policies developed for the overall well-being of the elderly needs to be designed from an understanding of the perspectives of the elderly themselves.

In the South Asian context, despite the growing need for research on various aspects influencing the wellbeing of their elderly, studies on their perceived QoL is still a comparatively less explored area of research. Since, the senior citizens in these South Asian countries differ from the elderly in the western countries on their perspective to ageing (Brijnath, 2012; Lamb, 2014), the western models might not prove to be very effective in the assessment of their perceived QoL.

Among the South Asian countries, Indian elderly is estimated to contribute to $19 \%$ of India's total population by 2050, which is more than 324 million, i.e. more than the current population of all but five of the world's nations (Agarwal et al. 2016) as projected by the United Nations Population Division. The present study explores the perceptions of QoL from discussions and interviews with a group of Indian elderly residing in the city of Kolkata, India.

The study identifies the broad domains and their respective set of sub-domains or factors, which can be used for the development of a QoL index for assessment of QoL of Indian elderly. The broad domains identified in this study was based on the assumption that people often interlink seemingly similar qualitative aspects of life during their assessment and evaluate them on the basis of concepts that are not directly observable (Bollen, 2002).

The methodology adopted for arriving at the study objectives has been discussed in the next section.

\section{Methodology}

The complete methodology for this study can be divided into five steps.

1. Compiling an initial list of broad domains associated with the QoL of elderly, identified from the study of the items used for the assessment of QoL of elderly in existing scales or QoL instruments. (discussed in Section 2a).

2. Identification of an initial list of factors associated with each of these domains from the study of QoL instruments, theories on ageing, research on aged, and studies on Indian elderly. (discussed in Section 2b).

3. A focus group using the broad domains identified in the previous step to update and validate the identified list of factors (in the first step from literature), based on the perspectives of the Indian elderly. (discussed in Section 2c).

4. Refinement and item reduction through discussion and identification of a final list of factors influencing the QoL of Indian elderly from the results obtained from the first and second steps. (discussed in Section 2d).

5. The final round of survey conducted on 408 Indian elderly respondents across all socio-demographic groups to arrive at the final set of domains and their respective set of factors influencing the perceived QoL of Indian elderly. (discussed in Section 2e).

2.a. Identification of initial list of broad domains of QoL 
The existing QoL measurement models or QoL scales or QoL instruments have conceptualized the dimensions of QoL based on the purpose, scope, and context of their study and have been observed to be of two types: a) scales which measure several features of one's life and b) scales which are specific to the measurement of one or more aspects of the QoL of an individual. The existing instruments have conceptualized the dimensions of QoL based on the purpose, scope, and context of their study.

For the present research, 54 QoL instruments were identified from Halvorsrud and Kalfoss (2007), Haywood et al. (2005) on QoL measures for older people, a study by Linton et al. (2016) on review of well-being measures on adults, the wellbeing scales such as Flourish Index, Secure Flourish Index, Psychological Well-being Scale and Social wellbeing scale and few other QoL measures were identified from online searches on elderly specific QoL instruments (Authors, 2020). Approximated 1400 items were extracted from these 54 scales. The detailed questionnaires of the QoL instruments were studied to first identify the aspects of life each of the items in the questionnaire dealt with. Next, using the method of I-CVI (Item Content Validity-Index), a total of eight domains of QoL, namely, 1) a) Health (physical), b) Health (mental), 2) Social activities and relationships, 3) Leisure activities, 4) Level of independence, 5) Life and Self perceptions affecting emotional well-being, 6) Religious/ spiritual beliefs, 7) Financial stability and 8) Support from neighbourhood or surrounding built environment were identified (Authors, 2020). Authors (2020) discusses in detail the process for identification of QoL domains from QoL scales using the technique of I-CVI. In this paper, since we are identifying factors which can be influenced by the neighborhood environment, we shall discuss in detail only about the factors for the QoL domains 1 to 7.

\section{2.b. Identification of initial list of factors of QoL}

\section{2.b.i. Research on ageing and theories of ageing}

Ageing has been viewed both from optimistic and pessimistic perspectives leading to different types of dualisms in the theories of aging (Andrew, 2008).

The existing theories on ageing can be classified under the broad domains of biological and socio-psycho-social theories. In this study, we have considered some of the psycho-social theories on ageing, because the focus of the present study is to understand perceived QoL.

\section{2.b.ii. Research on ageing and QoL of elderly in India}

Studies on medical and biological sciences have identified the different ailments associated with old age and issues related to access to health care. The perception of the elderly in India have been observed to be changing in modern societies. The traditional Indian family, where the elderly were consulted for their wisdom and considered for important family decisions, (Krishnaswamy et al., 2008), are in some instances, now considered as burden due to their limited capabilities, leading to increased dependence (Prakash, 1999). Research on Indian elderly in context of the socio-cultural influences include studies on successful aging, disability, coping, nature and characteristics of centenarians, etc.(Panruti, Liebig, \& Duvvuru, 2015). Age, marital status, gender, educational background, living arrangement, have been observed to influence the QoL of Indian elderly.

There is a limitation in the quality and quantity of studies on development of a holistic scale or instrument for the measurement of QoL of Indian elderly.

\section{2.c. Focus group survey}

The detailed process of focus group discussion, the analysis technique and the discussion of the results is elaborated in Authors (2020). A brief overview of the survey process is provided in this section. Semi-structured interviews were conducted in ten different neighbourhoods in the city of Kolkata, India on 83 elderly respondents. Only elderly people who were physically and mentally capable of actively participating in the complete interview process were included in the survey. The discussion started with an introduction to the purpose of the survey and the type of questions that were to be asked. The identity (name, address, etc.) of the respondents was not recorded to keep the responses anonymous. During the introduction, it was also mentioned that the respondents were free to not respond to questions when they felt uncomfortable or unwilling to answer the same. The respondents were also free to leave the interview process if they felt uncomfortable or disinterested. In the focus group survey, respondents belonging to the age group of 55-59, were also considered because their opinions can help in the formulation of the needs of the future generation of the elderly. The interview questions focused on the experience of respondents on the initial list of identified QoL domains, and how the experiences had changed with the onset of old age. Both positive and negative experiences were noted to identify the factors associated with each QoL domain. The responses were analysed with content analysis; a 
descriptive approach to analyse qualitative data. The focus group survey resulted in the identification of 47 QoL factors for all QoL domains (1 to 7, as mentioned in Section 2a).

\section{2.d. Determination of final list of QoL factors}

The final list of QoL factors identified for each QoL domain, from focus group survey, study of QoL scales and theories on ageing and aged, were first listed together, followed by a stage of refinement of these factors. An item reduction technique, based on discussion, was applied in this stage to consolidate the findings from literature (scales, theories) and focus group survey.

Factors catering to similar aspects of life were combined together to arrive at a final list of 37 factors. The factors were framed in a way to enable satisfaction based questions to be asked with respect to each of these factors.

Table 1: Identification of final list of QoL factors after item reduction and item refinement 


\begin{tabular}{|c|c|}
\hline QoL Domain & Final QoL sub-domain/ factors \\
\hline \multirow[t]{12}{*}{ Physical Health } & Ability to perform activities of daily living \\
\hline & Ability to perform instrumental activities of daily living \\
\hline & Body movement and mobility \\
\hline & Amount, type and quality of food intake \\
\hline & Quality of sleep \\
\hline & Ability of urinary control \\
\hline & Functioning of sensory abilities \\
\hline & $\begin{array}{l}\text { Ability to prevent health deterioration due to awareness of physical } \\
\text { and mental health issues }\end{array}$ \\
\hline & Your level of physical pain management \\
\hline & Ability to take care of diseases and ailments \\
\hline & Sense of safety from physical injury \\
\hline & Level of physical energy \\
\hline \multirow[t]{2}{*}{ Mental Health } & Mental health status \\
\hline & Cognitive functioning \\
\hline \multirow{14}{*}{$\begin{array}{l}\text { Life and Self perceptions affecting } \\
\text { emotional well-being }\end{array}$} & Self-worth and self-esteem \\
\hline & Level of engagement in varied activities in life \\
\hline & Feeling of helplessness \\
\hline & $\begin{array}{l}\text { Ability to cope with your feeling of helplessness (due to self and } \\
\text { worry over family's future) }\end{array}$ \\
\hline & Ability to manage emotions efficiently \\
\hline & Overall state of mind (Overall level of happiness) \\
\hline & $\begin{array}{l}\text { Sense of burden on others ( related to dependence on others for } \\
\text { daily and other basic activities) }\end{array}$ \\
\hline & Change in self-appearance due to old age \\
\hline & Ability to deal with fear of death \\
\hline & Ability to cope with your feeling of loneliness \\
\hline & Level of enthusiasm \\
\hline & Sense of safety from crime \\
\hline & $\begin{array}{l}\text { Sense of safety from social evils like elder abuse and financial } \\
\text { frauds }\end{array}$ \\
\hline & Ability of coping (adjusting to changes in life) \\
\hline \multirow[t]{2}{*}{ Financial stability } & $\begin{array}{l}\text { Ability to maintain condition of place of stay } \\
\text { Sense of burden on others ( related to financial dependence on } \\
\text { family members or others) }\end{array}$ \\
\hline & Ability to meet present and future needs with income \\
\hline Social relationship & $\begin{array}{l}\text { Companionship } \\
\text { Quality of social interaction }\end{array}$ \\
\hline \multirow[t]{3}{*}{ Level of Independence } & $\begin{array}{l}\text { Freedom to perform activities of choice } \\
\text { Level of dependence on health aids }\end{array}$ \\
\hline & Control over the activities in your life \\
\hline & Level of work load/ responsibilities \\
\hline Religious/ Spiritual Beliefs & $\begin{array}{l}\text { Ability to perform and conduct your personal religious / spiritual } \\
\text { beliefs and philosophy }\end{array}$ \\
\hline
\end{tabular}

\section{2.e. Identification of final structure of QoL domains and their respective list of factors from} interviews with 408 elderly respondents 
Convenience sampling technique was adopted for this study considering the length of the questionnaire, and the type of questions which required the respondents to invest a significant amount of time to reflect upon their life conditions. Convenience sampling is a type of non-probabilistic sampling where respondents are selected on the basis of certain requirements of the researcher, such as availability, accessibility, geographical proximity, or the willingness to participate in the study (Etikan, Musa, \& Alkassim, 2016).

\section{2.e.i. Study area selection for final survey with 408 respondents}

The study area selected for this research is Kolkata in the the state of West Bengal in India as it has been included as a member of the Global Network of Age-friendly Cities and Communities of World Health Organization (WHO, 2012). The study was conducted in different neighborhoods in Kolkata Municipal Corporation and the adjoining Bidhannagar Municipal Corporation, located in the state of West Bengal in India. The selection of study areas for this study was determined on the basis of the availability of respondents for the survey.

\section{2.e.ii. Survey question format and process of data collection}

The researcher was accompanied by survey team of five members, who were hired to conduct the survey. Similar to the focus group survey, the survey started with an introduction to the purpose of the survey and the type of questions that were to be asked. The identity (name, address, etc.) of the respondents was not recorded to keep the responses anonymous. During the introduction, it was also mentioned that the respondents were free to not respond to questions when they felt uncomfortable or unwilling to answer the same. The respondents were also free to leave the interview process if they felt uncomfortable or disinterested.

The purpose of the questionnaire and each of the questions, were explained in advance to each of the surveyors, in order to avoid any kind of mis-interpretations of the questions. Since the survey consisted of questions which required the respondents to introspect and reflect upon their lives, the survey required the surveyors to first get acquainted with the respondents. The survey process started with the surveyors first explaining the purpose of the survey, and the type of questions that will be asked during the survey. Any respondent who was not comfortable with the entire survey process were not included in the survey. Only respondents who agreed to respond to the survey, after the introduction session, and were mentally and physically capable to complete the entire survey process, which spanned for approximately 1 hour for each respondent, were included in the survey. Respondents were also informed that they could choose to not respond to any question they were uncomfortable with. Each questionnaire was translated to the local language, Bengali, which was the mother tongue of majority of the respondents. In some cases, questions had to be asked in Hindi. The questions consisted of satisfaction rating of QoL factors (identified in Table 1, Section 2d), in a scale of 1-5, where for the satisfaction scale, 1 meant least satisfied and 5 meant most satisfied.

\section{2.e.iii. Survey respondent characteristics}

Majority of the respondents belonged to Age group 1 (60-69), and only 11\% respondents belonged to Age group 3 (80 and above), which was because the survey required the elderly respondents who were healthy enough to sit through the long 1.5 hours' survey, and respond to all the questions efficiently. Only $28.9 \%$ of the respondents were female, which could be due to the fact that Indian female elderly are not comfortable to interact with strangers. $52.7 \%$ of the respondents were retired employees. $85 \%$ of the respondents were married, among which $66.4 \%$ of the respondents lived with their spouse and children. Only 1 elderly respondent lived with a nonfamily based care-giver (ayah or nurse or maid).

\section{2.e.iv. Identification of QoL domains and their respective list of factors}

\section{Result}

The satisfaction data on QoL factors and domains collected from the residents were analysed using Principal Component Analysis (PCA), a method of Exploratory Factor Analysis (EFA). This study uses Principal Component Analysis (PCA) with varimax rotation. The steps for PCA as followed in a study by Mazumdar and Paul (2016) was adopted in this research. PCA was conducted using the software SPSS. First, Bartlett's test of Sphericity was conducted and the correlation matrix was found to be an Identity Matrix, where all the diagonals are 1. Second, Kaiser-Meyer-Olkin (KMO) Measure of Sampling Adequacy was calculated, where the KMO value was observed to be 0.942 which is higher than the minimum acceptable value of 0.50 (shown in Table 2). Third, components were extracted using varimax rotation in factor analysis. Factors having Eigenvalue greater than 1 were retained. The criteria for consideration of items or variables as significant was variables with factor

Page $7 / 14$ 
loadings of 0.4 and above, as observed in studies by Bahari and Ling (2010); Chaplain (1995); Heung and Cheng (2000); Sidique, Lupi, and Joshi (2010).

Table 2: KMO and Bartlett's Test

\begin{tabular}{llr}
\hline \multicolumn{3}{c}{ KMO and Bartlett's Test } \\
\hline Kaiser-Meyer-Olkin Measure of Sampling Adequacy & .942 \\
Bartlett's Test of Sphericity & Approx. Chi-Square & 6148.084 \\
\cline { 2 - 3 } & $\mathrm{df}$ & 666 \\
\cline { 2 - 3 } & Sig. & 0.000 \\
\hline
\end{tabular}

The exploratory factor analysis yielded 7 components. The cumulative variance explained by the components is $54.929 \%$. The variable groupings is shown in Table 3. Each component was assigned a name on the basis of the variables that grouped together to form the same.

Table 3: Results of Principal Component Analysis 
Component 1: Health status (physical and mental) influencing performance of activities

Cronbach Alpha : 0.891; \% Variance explained: 33.385; Eigenvalue: 12.352

i. $\quad$ Ability to perform activities of daily living

ii. $\quad$ Body movement and mobility

iii. Ability to perform instrumental activities of daily living

iv. Level of physical energy

v. Ability to take care of diseases and ailments

vi. Control over the activities in your life

vii. Level of physical pain management

viii. Cognitive functioning

ix. $\quad$ Freedom to perform activities of choice

x. Sense of burden on others ( related to dependence on others for daily and other basic activities)

xi. $\quad$ Functioning of Sensory abilities

xii. Ability to prevent health deterioration due to awareness of physical and mental health issues

xiii. Amount, type and quality of food intake

Component 2: Psychological state

Cronbach Alpha : 0.813; \% Variance: 4.4.30; Eigenvalue: 1.639

i. $\quad$ Overall state of mind

ii. $\quad$ Ability to cope with your feeling of loneliness

iii. Ability to cope with your feeling of helplessness (due to self and worry over family's future)

iv. Level of work load/ responsibilities

v. Ability to perform and conduct your personal religious/ spiritual beliefs and philosophy

vi. Level of enthusiasm

vii. $\quad$ Ability to manage expression of emotions efficiently

viii. Mental health status

Component 3: General perceptions associated with old age

Cronbach Alpha : 0.769; \% Variance: 4.217; Eigenvalue: 1.560

i. $\quad$ Change in self-appearance due to old age

ii. $\quad$ Ability to deal with fear of death

iii. $\quad$ Sense of safety from social evils like elder abuse and financial frauds

iv. Sense of safety from crime

v. Dependence on health aids

Component 4: Financial status

Cronbach Alpha : 0.711; \% Variance: 3.816; Eigenvalue: 1.412

i. $\quad$ Sense of burden on others ( related to financial dependence on family members or others)

ii. Ability to meet present and future needs with income

iii. $\quad$ Ability to maintain the condition of place of stay

Component 5: Involvement in activities and social relationships

Cronbach Alpha : 0.661; \% Variance: 3.221; Eigenvalue: 1.192

i. Level of engagement in varied activities

ii. Ability to protect self from physical injury

iii. Ability of coping (adjusting to changes in life)

iv. Self-worth and self-esteem

Component 6: Quality of companionship

Cronbach Alpha : 0.669; \% Variance: 3.022; Eigenvalue: 1.118

i. Companionship

ii. Quality of social interaction

Component 7: Quality of sleep 
i. Quality of sleep

ii. Ability of urinary control

Extraction Method: Principal Component Analysis.

Rotation Method: Varimax with Kaiser Normalization.

a. Rotation converged in 14 iterations.

\section{Discussion}

The findings validate the assumption that the perception of the Indian elderly about the factors influencing their QoL is significantly dissimilar from those developed in the European or American context. Comparison of the QoL domain and factor structure obtained in Table 3 with that derived in Table 1 reveal that the groupings observed from Principal Component Analysis vary considerably from that which was developed from literature study and focus group discussion. While, Quality of sleep and Quality of companionship are observed to be specific domains of importance in the QoL of Indian elderly, religious/ spiritual activities which are assumed to be separate domains of importance to the elderly, have been clubbed with the factors influencing the domain of Psychological state.

Health status (physical and mental) influencing performance of activities, Psychological state, General perceptions associated with old age, Financial status, Involvement in activities and social relationships, Quality of companionship and Quality of sleep are the major domains (revealed from the components identified from PCA), which the Indian elderly associate with their QoL. The following section discusses the findings for each component or QoL domain.

Component or Domain1: Health status (physical and mental) influencing performance of activities

The factors associated with physical and mental health, influencing the ability to perform activities have been observed to group together to form this domain. Since cognitive functioning influences one's efficiency in the performance of activities, it has also grouped under this domain (Hall, Vo, Johnson, Barber, \& O'Bryant, 2011).

Component or Domain 2: Psychological state

The factors that influence an individual's ability to maintain their overall psychological state of mind is observed to have the strongest influence in this domain. The other variables which have grouped together, are related to the emotional or psychological well-being of an elderly.

Component or Domain 3: General perceptions associated with old age 
The factors most commonly linked to the image of old age forms this domain. The vulnerability of the elderly to crime and abuse and recent upsurge in crimes on elderly victims in the Indian context, is probably the reason why these variables have also associated together.

\section{Component or Domain 4: Financial status}

The variables related to the ability of an individual to cater to their basic needs and desires based upon the economic resources available to them have associated to form this domain.

\section{Component or Domain 5: Involvement in activities and social relationships}

The factors associated to form this domain corroborate with the sociometer theory, which states that an individual's self-esteem is often strongly influenced by the reactions of people associated with them. Each of the variables which have associated to form this domain, mutually influence each other, and determine the degree to which an individual wishes to participate in social activities and building social relationships.

\section{Component or Domain 6: Quality of companionship}

The respondents in this study links both the objective characteristics (degree of companionship, i.e. if they have or do not have sufficient companionship) and the quality of relationship, as an important factors influencing their companionship, similar to the Convoy model.

\section{Component or Domain 7: Quality of sleep}

The variables which load on Component 7 relates to sleep related disorders like Nocturia, which affects the Quality of sleep in elderly, which was observed to be a factor included in domain of Health in existing scales.

\section{Conclusion}

The present study aims at identifying the broad QoL domains and their respective list of factors, which can be used for the assessment of the perceived QoL of Indian elderly and for improving the same in the neighbourhood context. The present study has two major contributions: first, the incorporation of existing literature on QoL along with the direct perceptions of the Indian elderly for the determination of a list of QoL factors influencing the Indian elderly and second, the identification of QoL factors which can 
be supported by required infrastructure in the neighbourhood context. The first contribution includes both the identification of a list of 37 QoL factors, and a broader list of seven QoL domains, to which these factors contribute to. These findings validate the need for the study by establishing that the structure of domain and factors influencing perceived QoL of the Indian elderly, vary considerably from that of the models on QoL of elderly developed in the European or American context. The QoL domain and factor structure can be considered to be the third contribution of this study, which can be further explored on a larger sample size for the development of a QoL index specific to the needs of the Indian elderly, and which can be catered to in the neighbourhood context. The second contribution can be of immediate use to policy makers who can involve planners to frame neighbourhood development guidelines to cater to the list of QoL factors, identified in this study.

\section{Additional Note And Declarations}

- No conflict of interest.

- This manuscript is an abridged version of the manuscript 'Exploring the broad domains influencing perceived Quality of Life (QoL) of elderly in the context of their neighbourhoods: a case study of Kolkata, India', presently submitted for review. The abridged version was prepared only to be uploaded for preprint.

- Since the survey conducted in this research is a part of a research project being conducted at IIT Kharagpur, India, the concerned authorities were informed prior to the survey. For the surveys conducted in housing complexes, a letter explaining the purpose and type of the survey was first submitted to a member/ chairman/ head of the housing/ society and the surveys could be conducted only after they permitted us to conduct the survey. Before starting the survey in all the study areas, all the participants were explained about the purpose of the survey, the type of questions to be asked, the approximate time duration of the survey and shown the questionnaire format and then the participants were included in the survey only if they gave their verbal consent to the survey. They were also explained that they could leave the survey if they felt uncomfortable or disinterested at any point of time, and could choose to not answer any question against their willingness. Besides, the personal details (names, address, etc.) of the participants were not documented. In the end of each survey, the responses were summarized and read out to the participants.

\section{Acknowledgement:}


This paper is a part of a doctoral thesis on identifying urban neighborhood level infrastructure catering to the QoL of Indian elderly, submitted at Indian Institute of Technology Kharagpur, India. The first author had conducted the research work for this paper during her Ph.D at the Department of Architecture and Regional Planning, IIT Kharagpur, India and she was a recipient of the institute scholarship (from IIT Kharagpur) during her Ph.D. The research conducted in this paper is also a part of the research projectImproving Quality of Life of Senior Citizens in Residential Neighbourhoods in an Indian Context (Project Code: LCR), under the mega project Future of Cities at Indian Institute of Technology (IIT), Kharagpur, India, supported by the Ministry of Human Resource Development (MHRD), India. The survey for this paper was funded from the project, LCR. The authors sincerely thank Indian Institute of Technology (IIT), Kharagpur, India and MHRD, India for providing the necessary facilities and opportunities to prepare this research paper and funding the research program.

\section{References}

1. Agarwal, Arunika, Lubet, Alyssa, Mitgang, Elizabeth, Mohanty, Sanjay, \& Bloom, David E. (2016). Population Aging in India: Facts. Issues, and Options.

2. Andrew, W. (2008). A Metahistorical Perspective on Theories of Aging. Handbook of Theories of Aging, 25.

3. Bahari, Mohd Baidi, \& Ling, Yip Wai. (2010). Factors contributing to customer satisfaction with community pharmacies in Malaysia. Journal of Public Health, 18(1), 35-41.

4. Brijnath, Bianca. (2012). Why does institutionalised care not appeal to Indian families? Legislative and social answers from urban India. Ageing \& Society, 32(4), 697-717.

5. Chaplain, Roland P. (1995). Stress and job satisfaction: A study of English primary school teachers. Educational psychology, 15(4), 473-489.

6. Etikan, Ilker, Musa, Sulaiman Abubakar, \& Alkassim, Rukayya Sunusi. (2016). Comparison of convenience sampling and purposive sampling. American journal of theoretical and applied statistics, 5(1), 1-4.

7. Hall, James R, Vo, Hoa T, Johnson, Leigh A, Barber, Robert C, \& O'Bryant, SE. (2011). The link between cognitive measures and ADLs and IADL functioning in mild Alzheimer's: what has gender got to do with it? International Journal of Alzheimer's Disease, 2011.

8. Halvorsrud, Liv, \& Kalfoss, Mary. (2007). The conceptualization and measurement of quality of life in older adults: a review of empirical studies published during 1994-2006. European journal of ageing, 4(4), 229-246.

9. Heung, Vincent CS, \& Cheng, Eliza. (2000). Assessing tourists' satisfaction with shopping in the Hong Kong special administrative region of China. Journal of Travel Research, 38(4), 396-404.

10. Kalavar, Jyotsna M, \& Jamuna, Duvvuru. (2008). Interpersonal relationships of elderly in selected old age homes in urban India. Interpersona: An International Journal on Personal Relationships, 2(2), 193-215. 
11. Krishnaswamy, B, Sein, U Than, Munodawafa, Davison, Varghese, Cherian, Venkataraman, Kavita, \& Anand, Leslie. (2008). Ageing in India. Ageing International, 32(4), 258-268.

12. Lamb, Sarah. (2014). Permanent personhood or meaningful decline? Toward a critical anthropology of successful aging. Journal of Aging Studies, 29(Supplement C), 41-52. doi: https://doi.org/10.1016/j.jaging.2013.12.006

13. Mazumdar, Jublee, \& Paul, Saikat Kumar. (2016). Socioeconomic and infrastructural vulnerability indices for cyclones in the eastern coastal states of India. Natural Hazards, 82(3), 1621-1643.

14. Nilsson, Jan, Grafström, Margareta, Zaman, Shahaduz, \& Kabir, Zarina Nahar. (2005). Role and function: Aspects of quality of life of older people in rural Bangladesh. Journal of Aging Studies, 19(3), 363-374. doi: https://doi.org/10.1016/j.jaging.2004.07.006

15. Panruti, Ramamurti V, Liebig, Phoebe S, \& Duvvuru, Jamuna. (2015). Gerontology in India. The Gerontologist, 55(6), 894-900.

16. Prakash, Indira Jai. (1999). Ageing in India: World Health Organization Geneva.

17. Sidique, Shaufique F, Lupi, Frank, \& Joshi, Satish V. (2010). The effects of behavior and attitudes on drop-off recycling activities. Resources, conservation and recycling, 54(3), 163-170.

18. Ugargol, Allen Prabhaker, Hutter, Inge, James, KS, \& Bailey, Ajay. (2016). Care needs and caregivers: Associations and effects of living arrangements on caregiving to older adults in India. Ageing international, 41(2), 193-213.

19. WHOQOLGroup. (1995). The World Health Organization quality of life assessment (WHOQOL): position paper from the World Health Organization. Social science \& medicine, 41(10), 1403-1409. 